\title{
Phylogeographical analysis reveals multiple conservation units in brook lampreys Lampetra planeri of Portuguese streams
}

\author{
A. M. Pereira* + †, J. I. Robalo*, J. Freyhof $\$$, C. Maia*\|, J. P. Fonseca*, \\ A. Valente*II and V. C. Almada* \\ *Unidade de Investigação em Eco-Etologia, Instituto Superior de Psicologia Aplicada. Rua \\ Jardim do Tabaco 44, 1149-041 Lisboa, Portugal, †CIMAR/CIIMAR, Centro Interdisciplinar \\ de Investigação Marinha e Ambiental. Universidade do Porto. Rua dos Bragas 289, \\ 4050-123 Porto, Portugal, §Leibniz-Institute of Freshwater Ecology and Inland Fisheries, \\ IGB, Dept.4, Biology and Ecology of Fishes, 12587 Berlin, Müggelseedamm 310, Germany, \\ ||Planeta Vivo - Centro de Investigação Ambiental, Travessa da Cedofeita, 62 4050-448 \\ Porto, Portugal and IDepartamento de Zoologia e Antropologia, Faculdade de Ciências, \\ Universidade do Porto. Praça Gomes Teixeira, 4099-002 Porto, Portugal
}

(Received 12 October 2009, Accepted 23 March 2010)

\begin{abstract}
The populations of brook lamprey Lampetra planeri of Portuguese Rivers were analysed phylogeographically using a fragment of $644 \mathrm{bp}$ of the mitochondrial control region of 158 individuals from six populations. Samples representing L. planeri and migratory lampreys Lampetra fluviatilis of rivers draining to the North Sea and the Baltic Sea were also included to assess the relationships of Portuguese samples. The data support a clear differentiation of all the populations studied. Several populations, which are isolated among themselves and also from the migratory lampreys, proved to be entirely composed of private haplotypes, a finding that supports some time of independent evolutionary history for these populations. This, combined with the geographic confinement to small water bodies, justifies the recognition of at least four conservation units in the Portuguese rivers Sado, São Pedro, Nabão and Inha.

(C) 2010 The Authors

Journal compilation (c) 2010 The Fisheries Society of the British Isles
\end{abstract}

Key words: allopatric speciation; conservation units; Lampetra; phylogeography; Portugal.

\section{INTRODUCTION}

Lampreys (Petromyzonidae) are remarkable not only for their assortment of very primitive characters but also for their diverse life histories and patterns of speciation (Hardisty, 2006). All lampreys spawn in fresh water and have a larval phase that typically lasts for several years. The eyeless ammocoetes, which are filter feeders, live buried in the sediment. After metamorphosis, their development may take one of two courses: (1) individuals may migrate downstream spending one or more years in the sea or lakes, where they adopt a parasitic or predatory way of life. Upon the

\$Author to whom correspondence should be addressed. Tel.: +35 1218811726; fax: +35 1218860954; email: ana_pereira@ispa.pt 
approach of sexual maturation, they migrate back into fresh water where they spawn and die; (2) alternatively, recently metamorphosed lampreys may remain in fresh water without feeding, reaching sexual maturity at a much smaller size, spawning and dying after a short period (Kottelat \& Freyhof, 2007).

While the majority of extant lamprey genera include one or more migratory species, in most of them non-migratory forms are also present (Lang et al., 2009). This observation indicates that the shift between the two life-history patterns occurred independently several times in lamprey evolution. Non-migratory forms are viewed as derived from the migratory ones, leading to the concept of paired or satellite species (Zanandrea, 1959; Vladykov \& Kott, 1979).

There is still a considerable debate about the taxonomic status of at least some of the non-migratory species. Exchange of genes between the two forms has not been ruled out in areas where they occur sympatrically (Schreiber \& Engelhorn, 1998). On the other hand, it has been suggested that different environmental conditions could trigger different life histories, a situation that would not by itself exclude the role of genetic factors in the determination of different ontogenetic pathways (Kucheryavyi et al., 2007). Additionally, some authors considered that the same species could be polymorphic for feeding type and life history (Manion \& Purvis, 1971; Beamish, 1987).

In Western Europe, two species of the genus Lampetra have been traditionally recognized: the lampera or river lamprey Lampetra fluviatilis (L.) and the brook lamprey Lampetra planeri (Bloch).

Lampetra fluviatilis is composed of predatory migratory fish, mostly distributed in north-west Europe, from western France and the British Isles to Scandinavia, spawning in rivers draining to the Atlantic Sea, North Sea and Baltic Sea. In south-west Europe, it is absent from Spain, where the last record of its presence dates back to 1974 in the Tagus drainage (Doadrio, 2001). In Portugal, there are apparently few records in recent years, although its previous presence in the Tagus is well documented (Doadrio, 2001).

Lampetra planeri, a non-parasitic and non-migratory fish, occupies a similar range in the fresh waters of north-west Europe and is absent from Spain, except for a stream close to the French border in the Pyrenees (Doadrio, 2001). In Portugal, many populations ascribed to this species are found in numerous rivers and streams (Cabral et al., 2005). Some populations are present in Italy (Kottelat \& Freyhof, 2007).

Both species have been assigned various levels of protection in western European countries (Kelly \& King, 2001). In Portugal, fish of the genus Lampetra were considered critically endangered by Cabral et al. (2005).

Blank et al. (2008) compared a substantial number of mitochondrial genes and found that none of them could serve to detect consistent differences between $L$. fluviatilis and L. planeri in the area where both co-occur, a finding that points either to a persistent gene flow between forms or to a differentiation process which is so recent that lineage sorting in mtDNA has not yet taken place.

Espanhol et al. (2007), using mtDNA (ATPase 6, 8 and cytochrome $b$ genes), demonstrated that L. planeri is polyphyletic, and thus, according to the phylogenetic species concept, does not correspond to a valid species. They showed that L. planeri possesses haplotypes that are shared with $L$. fluviatilis and others that are derived by numerous independent pathways from L. fluviatilis. Although these authors used only a few samples per river, they also showed that several Portuguese haplotypes 
of non-migratory lampreys are quite distinctive and may represent ancient branches in the radiation of Lampetra.

The study of Espanhol et al. (2007) included only a small number of samples per drainage, which precludes any phylogeographic analysis. A population approach, however, is urgently needed in terms of conservation, because many Portuguese populations are confined to small or very small streams and are isolated from the sea. Therefore, they are reproductively isolated from other populations and, according to the results of Espanhol et al. (2007), may represent evolutionary units.

In this article, a fragment of the control region of the mtDNA was used to compare several Portuguese L. planeri populations, their genetic diversity, their level of differentiation and their relationships with north European populations.

\section{MATERIALS AND METHODS}

\section{SAMPLING}

DNA sequences were obtained from 267 individuals for the control region (GenBank accession numbers from EU595965 to EU596199 and from GQ340523 to GQ340554; for collection site locations, see Fig. 1). Ammocoetes and adults were collected by electrofishing. While the ammocoetes of migratory and non-migratory Lampetra are not easily distinguishable, the

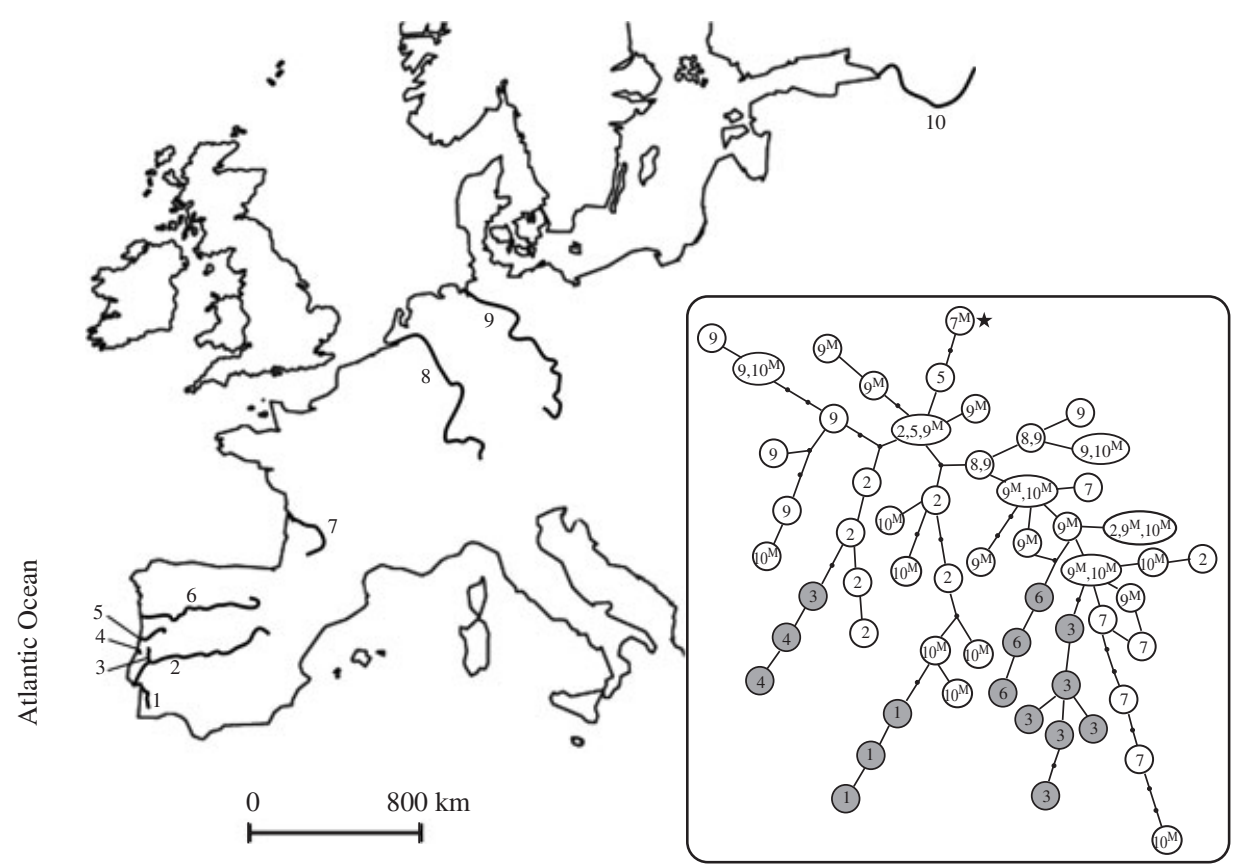

FIG. 1. Map with collection site locations and haplotype network. Haplotype number identifications refer to rivers. 1, Sado; 2, Tagus; 3, Nabão; 4, São Pedro; 5, Mondego; 6, Inha; 7, Garonne; 8, Elbe; 9, Rhine; 10, Neva. Haplotypes of migratory Lampetra fluviatilis are identified with superscript M. * corresponds to the GenBank accession number Y18683. Private haplotypes present in the Portuguese populations suggested as conservation units in this article (see Discussion section) are marked with grey. 
mature adults are readily classified according to size and morphology. The diagnostic criteria given by Kottelat and Freyhof (2007) were used. Ammocoetes from populations of drainages where there are no records of predatory lamprey were assigned to the non-migratory form. These include the Rivers Sado, Nabão, São Pedro, Mondego and Inha. In all these rivers, all the adults captured were small non-migratory lampreys. Because of the historical presence of the migratory form in the Tagus River, the absence of migratory fish was not sure and refrained from classifying them as migratory or non-migratory.

\section{MOLECULAR PROCEDURES}

Total genomic DNA was extracted from fin clips or pieces of muscle preserved in ethanol by an SDS-proteinase-k-based protocol (Sambrook et al., 1989 with modifications). A total of 644 base pairs (bp) of the control region (non-coding region I according to Blank et al., 2008) were amplified using the primers LampFor $5^{\prime}$-ACACCCAGAAACAGCAACAAA- $3^{\prime}$ and LampRev 5'-GCTGGTTTACAAGACCAGTGC-3' (Almada et al., 2008). PCR conditions followed Almada et al. (2008). Sequencing reactions were performed in StabVida on a 3700 ABI DNA sequencer (Applied Biosystems; www.appliedbiosystems.com) using the Big Dye terminator DNA sequencing kit (http://www.stabvida.com).

\section{DATA ANALYSIS}

Sequences were aligned with Clustal X (Thompson et al., 1997). In the control region, an indel of $39 \mathrm{bp}$ was widespread, which is homologous to part of the repetitive motif described by White and Martin (2009) in Lampetra (Okkelbergia) aepyptera (Abbott). The insertion had a conserved sequence and did not vary in the number of repeats, and most populations were polymorphic for the indel. Thus, it was coded as a transversion to make the data amenable to subsequent analysis.

Phylogenetic analysis was performed with PAUP 4.0b10 (Swofford, 2003) using maximum parsimony (MP). Relationships among haplotypes were analysed with a parsimony network estimated by the software TCS version 1.18 (Clement et al., 2000). Because the river Inha was comparatively overrepresented (49 samples) with only three haplotypes, the number of samples included in the haplotype network was reduced to 32. Care was taken to ensure that the reduction kept the relative frequency of haplotypes constant and that all of them were included.

Arlequin software package version 3.01 (Excoffier \& Schneider, 2005) was used to estimate genetic diversity indices, to assess population differentiation and to perform a Mantel test between geographic and $F_{\mathrm{ST}}$ values and an analysis of molecular variance (AMOVA; Excoffier et al., 1992). Mean numbers of inter-population pair-wise differences were corrected by subtracting the average within-population differences for the populations of each pair. To further test the relationships among populations, the corrected mean number of pairwise differences was used to perform a multidimensional scaling using the software SPSS 16.0 (SPSS Inc., 2008).

\section{RESULTS}

A total of 267 sequences were obtained. The number of variable sites was 31 (one of which corresponds to an indel of $39 \mathrm{bp}$, coded as a transversion, see Materials and Methods for further details), of which 20 were parsimony informative. Fifty-eight haplotypes were found. The average percentage of divergence among haplotypes was $1.97 \%$ (corresponding to 11 differences), while the most divergent haplotypes differed by $2 \cdot 16 \%$ (corresponding to 13 differences).

In Table I, the number of samples, number of haplotypes, percentage of private haplotypes, genetic diversity indices and mean and maximum number of differences 


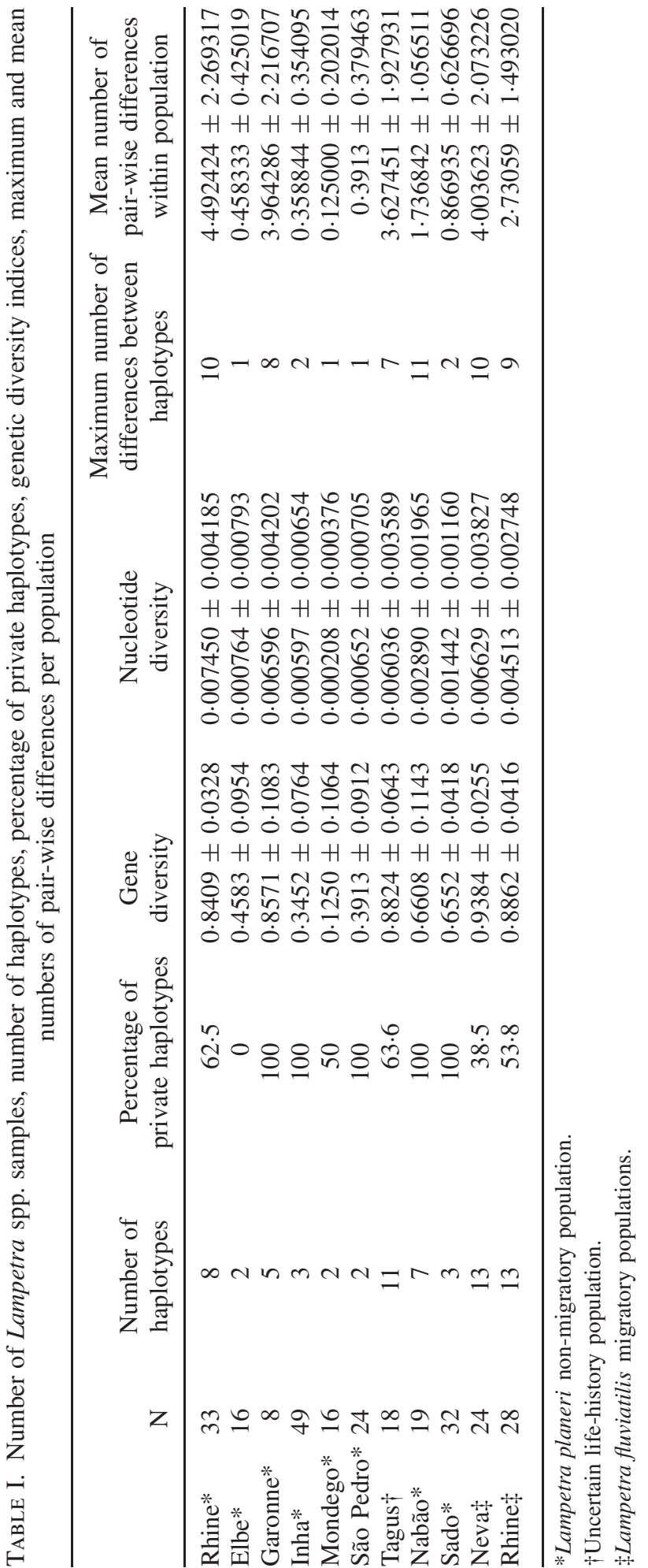


between haplotypes for each population are shown. Inspection of Table I shows that the highest levels of genetic diversity are found in populations of the Rivers Neva, Rhine, Garonne and Tagus, while the Portuguese Rivers Mondego, Inha, Nabão, São Pedro and Sado plus the Elbe population show the lowest genetic diversity levels. The percentage of private haplotypes reaches $100 \%$ in Rivers Sado, Nabão, Inha, São Pedro and Garonne. Thus, the Rivers Sado, São Pedro, Inha and Nabão in Portugal stand out for both the low levels of genetic diversity and the presence of private haplotypes. The Mantel test failed to detect a correlation between geographic and genetic distances among populations (correlation coefficient $=-0.302 ; P>0.05$ ), providing evidence against an isolation by distance model of population differentiation. Indeed, the most distinct populations are found in a restricted geographical area in Portugal.

An AMOVA including all populations detected significant inter-population variation $(\mathrm{Va}=2 \cdot 01047 ; P<0.001 ; \mathrm{Vb}=0.96110)$.

In Table II, the net average differences among all pairs of populations and the corresponding $F_{\mathrm{ST}}$ values are shown. Both values were significant for all pairs of populations, also allowing for a Bonferroni correction. It is interesting to note that, even within the same drainage, significant differences could be detected among populations, although with low-to-moderate $F_{\mathrm{ST}}$ values. These are the cases of the migratory and non-migratory fish from the Rhine and those of the Tagus and its tributary Nabão. The highest $F_{\mathrm{ST}}$ values were those found in comparisons involving the Sado population, and this was also true for net average differences. A very high level of population differentiation was also found in comparisons involving the São Pedro River.

In Fig. 2, the relationships among populations are summarized using a multidimensional scaling based on the corrected average pair-wise differences (stress $=0 \cdot 1240$; $\mathrm{RSQ}=0.9513$ ). Inspection of Fig. 2 reveals two salient features: there is a grouping near the centre of the graph, which includes migratory and non-migratory fishes from the Rhine, and samples from the Neva, Garonne, Tagus and Mondego rivers. Several Portuguese populations of small rivers occupy very peripheral positions and are also quite separated from each other.

Maximum parsimony analysis produced 50000 equally parsimonious trees, which failed to recover the distinction between migratory and non-migratory lampreys, confirming the results of Espanhol et al. (2007). The MP trees were basically unresolved, except for a few haplotype groups with weak supports.

In Fig. 1, a parsimony haplotype network is presented. Inspection of this figure supports the following conclusions: (1) Lack of monophyly of the non-migratory. Indeed, L. planeri include haplotypes that were independently derived from haplotypes found in migratory L. fluviatilis at least nine times. Moreover, at least 3 haplotypes were shared between migratory and non-migratory forms. (2) The populations of the Rivers Sado, São Pedro, Inha, Nabão and Garonne, in which only private haplotypes were found, contained sequences that were derived from other haplotypes of the same river, strongly suggesting a considerable history of local independent evolution. Nabão and Garonne populations are polyphyletic, while the remaining three are monophyletic. (3) In contrast to these clades confined to specific rivers, several haplotypes found in migratory L. fluviatilis have a wide geographic distribution, with some found in the Tagus in Portugal and in the Neva near the Russian Baltic Sea. (4) In the Tagus, where migratory L. fluviatilis were recorded 


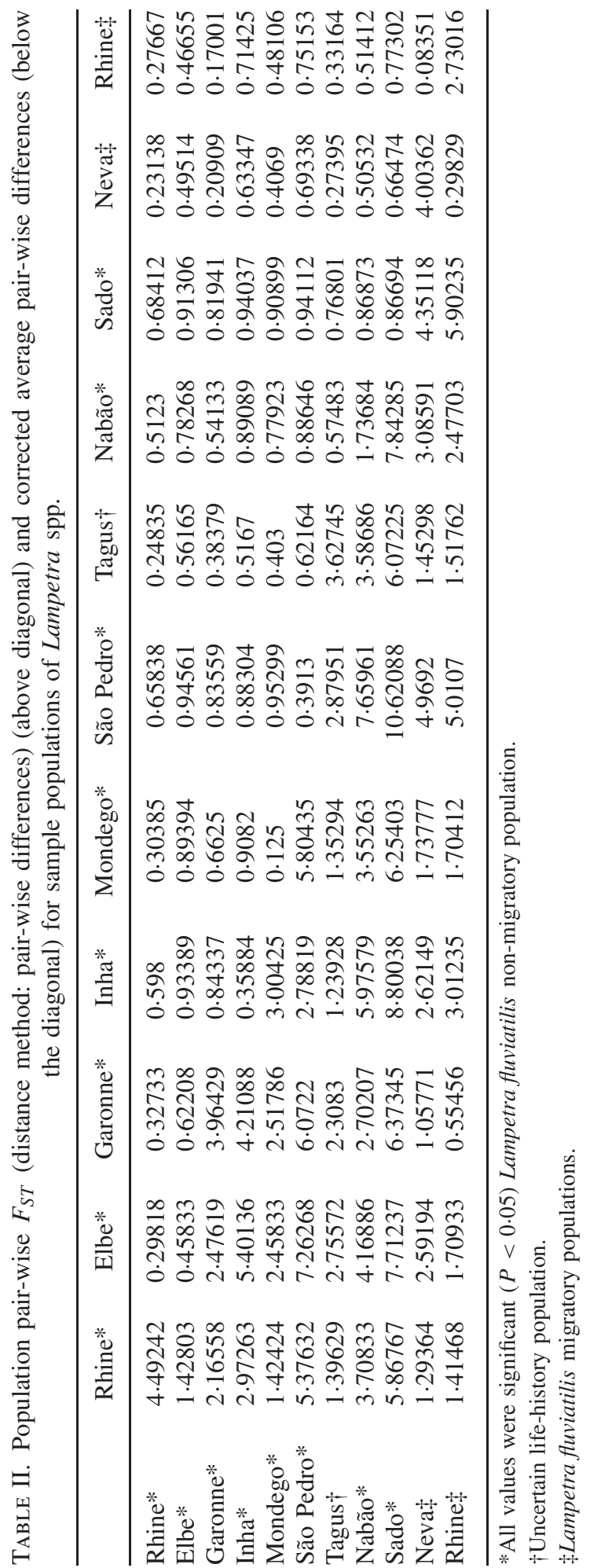


Euclidean distance model

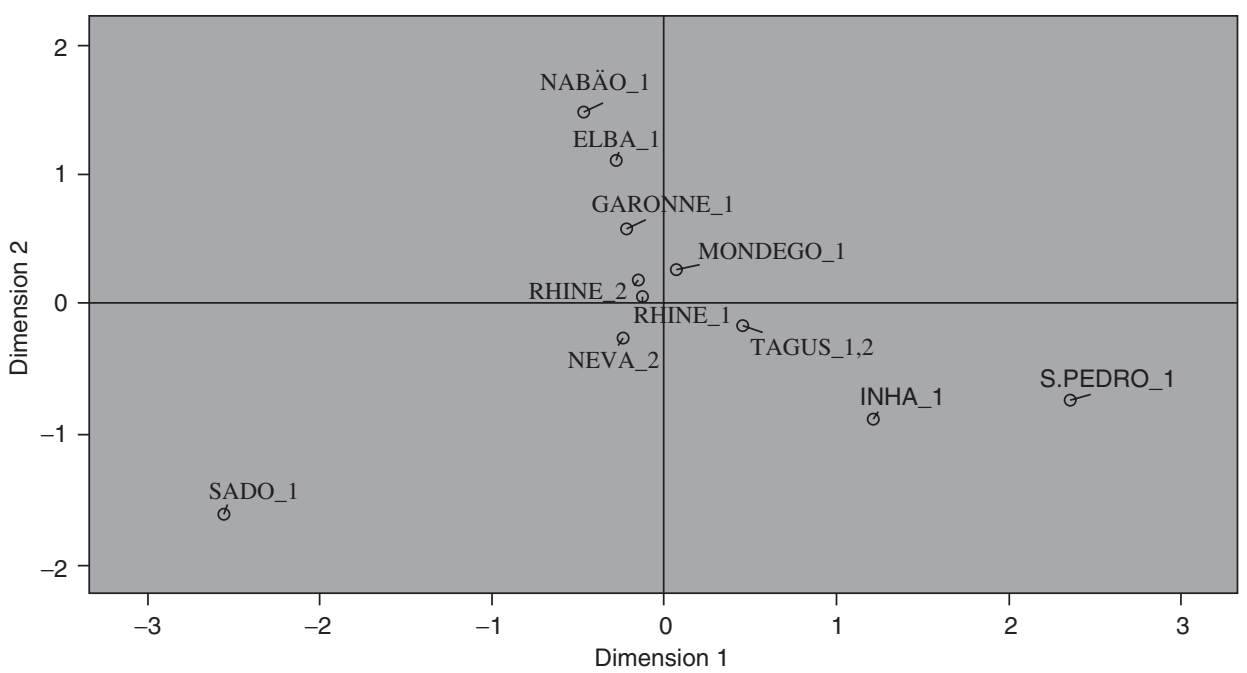

FIG. 2. Multidimensional scaling based on corrected average pair-wise differences between pairs of Lampetra spp. populations. 1, L. planeri non-migratory population; 2, Lampetra fluviatilis migratory populations. 1,2 , uncertain life-history population (population in which most specimens are non-migratory but the presence of some migratory individuals cannot be ruled out).

with some consistency until relatively recent dates, the haplotypes now present are shared or derived by very few steps from the ones found in migratory fish.

\section{DISCUSSION}

A striking result of the present study is the very high level of genetic diversity found in L. fluviatilis migrating to the North Sea and Baltic Sea. This finding stands in sharp contrast with the extremely low genetic diversity and lack of population differentiation in Petromyzon marinus L. samples collected in western Europe, from the Rhine to the Tagus, by Almada et al. (2008). Indeed, using the same DNA fragment, these authors found only 18 haplotypes in 273 specimens, in contrast with the 58 haplotypes in 267 specimens found in this study. This difference could be the result of the contrasting behaviour of P. marinus and the migratory L. fluviatilis. Indeed, P. marinus apparently lacks homing (Bergstedt \& Seelye, 1995), and P. marinus travel extensively in the sea, with a high probability of migrating to a river different from the one where they were born. This means that a large area such as the west coast of Europe may harbour a single gene pool, subjected to a common process of lineage sorting, likely to be especially severe during population bottlenecks. The behaviour of Lampetra may be conducive to a more rapid population differentiation and retention of a higher level of genetic diversity. It is known that L. fluviatilis tends to perform more restricted migratory movements than $P$. marinus, with individuals 
staying within or near the mouth of estuaries (Maitland, 2003). This migratory pattern may restrict but not suppress gene flow between rivers, favouring some level of population differentiation and retention of an overall higher level of genetic diversity, as haplotypes lost in a river by drift will likely persist in other drainages.

In glacial conditions, it is likely that migratory L. fluviatilis must have moved south, which would have increased their abundance in Portuguese rivers. In interglacials, like the present one, the bulk of the migratory populations must have moved northward again. In this situation, the Portuguese populations would have become increasingly isolated from the migratory fish from North Europe. The reduction of population size in small streams, combined with a lack of gene flow among rivers, would have favoured a rapid lineage sorting and loss of genetic diversity.

The low percentage of divergence among haplotypes of European Lampetra spp., when compared, for instance with the ones found in L. aepyptera (Martin \& White, 2008), another non-parasitic lamprey, and the finding that some Lampetra populations are polyphyletic are consistent with the hypothesis that brook lamprey populations in different Portuguese rivers may have originated from the migratory stock in relatively recent times during the Pleistocene. The polyphyletic populations could represent cases where lineage sorting did not take place yet, a condition that is typical of the initial stages of population isolation (Avise, 2000). An exception to this scenario of small localized populations getting isolated from a large migratory stock may be represented by the population of the River São Pedro, which contained haplotypes derived from the ones found in Nabão. The two rivers have their sources $<5 \mathrm{~km}$ apart, which means that minor geological changes may have allowed previous contacts between the two headwaters. This would identify dispersal among rivers as a less important, but plausible, process in L. planeri phylogeography, which agrees with the findings of Martin and White who found substantial phylogeographical structure in L. aepyptera.

The low overall level of divergence observed, and the use of a single marker, makes a discussion on the status of local populations as potential species obviously premature. Regardless of future conclusions on this point, this article describes mechanisms that, given sufficient time, will promote allopatric speciation sensu Futuyma (2005).

For the populations of the Rivers Sado, Inha and São Pedro, there is no evidence that migratory Lampetra were present in historical times, which means that it may be almost sure that gene flow does not exist among populations. On the other hand, even the mitochondrial data alone clearly demonstrate the distinctiveness and uniqueness of the Portuguese L. planeri populations, suggesting that the populations of the Rivers Sado, Nabão, São Pedro and Inha qualify as distinct conservation units following the Convention of Biological Diversity (CBD). They are composed of unique haplotypes, isolated from other populations, and are confined to small streams (in the Sado River, L. planeri only occur in a few tributaries), and are thus highly vulnerable to extinction if proper management action is not taken.

The need to recognize conservation units for these Portuguese L. planeri populations is made more urgent for two reasons. The first is that the total area of territory where Lampetra species are present is very small (Cabral et al., 2005). This means that population sizes are likely small. Secondly, these non-migratory lampreys occupy southern locations in the overall range of Lampetra spp. in western Europe and may 
have acquired adaptive traits favourable in the high temperature conditions where they live.

One could argue that these populations are the less valuable, from a conservation point of view, because of their very low level of genetic diversity, which contrasts with the high levels found in large rivers such as the Neva, Rhine and Tagus. The low genetic diversity, however, negates neither the distinctiveness of populations nor the possibility of independent evolutionary histories. Indeed, it may simply reflect a prolonged condition of low population size, with accelerated lineage sorting, due to the small habitat areas where these populations occur.

The population from the River Garonne also contained only private haplotypes. Because of small sample size, however, it is premature to draw conclusions on the status of this population or species. It is likely that a more comprehensive phylogeographical analysis of Lampetra spp. in western Europe may uncover additional populations with high levels of distinctiveness, restricted distributions and low gene flow with other populations.

One positive contribution of the present work is the demonstration that much more phylogeographic work must be undertaken to properly understand and conserve the genetic biodiversity of Lampetra spp. in Europe.

In conclusion, these data provide clear evidence supporting the genetic distinctiveness and consequent need for conservation of the Lampetra spp. populations of small Portuguese streams. It also demonstrates the need for detailed phylogeographical analysis of Lampetra spp. across its western European range.

We thank two anonymous referees for their very useful comments and suggestions. We also thank C. Sousa-Santos for her help and S. Chenu for the skilful technical assistance and N. Bogutskaya (St Petersburg), A. Nolte (Plön), M. Povz (Lubljana), C. Taverny (Gradignan), D. Turan (Rize) and F. Wagner (Jena) for providing us with preserved lamprey tissues. This work was supported by a grant from Iceland, Liechtenstein and Norway through the EEA Financial Mechanism and the Norwegian Financial Mechanism, by the project MarinERA 'Marine phylogeographic structuring during climate change: the signature of leading and rear edge of range shifting populations' and from the Eco-Ethology Research Unit (331/94) Pluriannual financing programme (Fundação para a Ciência e a Tecnologia). Collection of specimens complied with the current laws of each country.

\section{References}

Almada, V. C., Pereira, A. M., Robalo, J. I., Fonseca, J. P., Levy, A., Maia, C. \& Valente, A. (2008). Mitochondrial DNA fails to reveal genetic structure in sea-lampreys along European shores. Molecular Phylogenetics and Evolution 46, 391-396.

Avise, J. C. (2000). Phylogeography. Boston: Harvard University Press.

Beamish, R. J. (1987). Evidence that parasitic and nonparasitic life history types are produced by one population of lamprey. Canadian Journal of Fisheries and Aquatic Sciences 44, 1779-1782.

Bergstedt, R. A. \& Seelye, J. G. (1995). Evidence for lack of homing by sea lampreys. Transactions of the American Fisheries Society 124, 235-239.

Blank, M., Jurss, K. \& Bastrop, R. (2008). A mitochondrial multigene approach contributing to the systematics of the brook and river lampreys and the phylogenetic position of Eudontomyzon mariae. Canadian Journal of Fisheries and Aquatic Sciences 65, 2780-2790.

Cabral, H., Almeida, J., Almeida, P. R., Dellinger, T., Ferrand de Almeida, N., Oliveira, M. E., Palmeirim, J. M., Queiroz, A. I., Rogado, L. \& Santos-Reis, M. (Eds) (2005). Livro Vermelho dos Vertebrados de Portugal. Lisboa: Instituto da Consevação da Natureza. 
Clement, M., Posada, D. \& Crandall, K. A. (2000). TCS: a computer program to estimate gene genealogies. Molecular Ecology 9, 1657-1659.

Doadrio, I. (2001). Atlas y libro rojo de los peces continentales de España. Madrid: Dirección General de la Natureza - Museo Nacional de Ciencias Naturales.

Espanhol, R., Almeida, P. R. \& Alves, J. (2007) Evolutionary history of lamprey paired species Lampetra fluviatilis (L.) and Lampetra planeri (Bloch) as inferred from mitochondrial DNA variation. Molecular Ecology 16, 1909-1924.

Excoffier, L. G. L. \& Schneider, S. (2005). Arlequin ver. 3.0: an integrated software package for population genetics data analysis. Evolutionary Bioinformatics 1, 47-50.

Excoffier, L. G. L., Smouse, P. E. \& Quattro, J. M. (1992) Analysis of molecular variance inferred from metric distances among DNA haplotypes: application to human mitochondrial DNA restriction data. Genetics 131, 479-491.

Futuyma, D. J. (2005). Evolution. Suderland: Sinauer Associates.

Hardisty, M. W. (Ed.) (2006). Lampreys - Life Without Jaws. Ceredigion: Forrest Text.

Kelly, F. L. \& King, J. J. (2001). A review of the ecology and distribution of three lamprey species, Lampetra fluviatilis (L.), Lampetra planeri (Bloch) and Petromyzon marinus (L.): a context for conservation and biodiversity considerations in Ireland. Proceedings of the Royal Irish Acadademy 101B, 165-185.

Kottelat, M. \& Freyhof, J. (2007). Handbook of European Freshwater Fishes. Cornol: Kottelat.

Kucheryavyi, A. V., Savvaitova, K. A., Pavlov, D. S., Gruzdeva, M. A., Kuzishchib, K. V. \& Stanford, J. A. (2007) Variations of life history strategy of the arctic lamprey Lenthenteron camtschaticum from the Utkholok River (Western Kamchatka). Journal of Ichthyology 47, 37-52.

Lang, N. J., Roe, K. J., Renaud, C. B., Gill, H. S., Potter, I. C., Freyhof, J., Naseka, A. M., Cochran, P., Pérez, H. E., Habit, E. M., Kuhajda, B. R., Neely, D. A., Reshetnikov, Y. S., Salnikov, V. B., Stoumboudi, M. T. \& Mayden, R. L. (2009). Novel relationships among Lampreys (Petromyzontiformes) revealed by a taxonomically comprehensive molecular data set. American Fisheries Society Symposium 72, 41-55.

Maitland, P. S. (2003). Ecology of the River, Brook and Sea Lamprey. Conserving Natura 2000 Rivers Ecology Series No. 5. Peterbough: English Nature.

Manion, P. J. \& Purvis, H. A. (1971). Giant American brook lampreys, Lampetra lamottei, in the Upper Great Lakes. Journal of the Fisheries Research Board of Canada 28, $616-620$.

Martin, H. \& White, M. M. (2008). Intraspecific phylogeography of the least brook lamprey (Lampetra aepyptera). Copeia 2008, 579-585.

Sambrook, J., Fritsch, E. F. \& Maniatis, T. (1989). Molecular Cloning: A Laboratory Manual. Cold Spring Harbor, NY: Cold Spring Harbor Laboratory Press.

Schreiber, A. \& Engelhorn, R. (1998). Population genetics of a cyclostome species pair, river lamprey (Lampetra fluviatilis L.) and brook lamprey (Lampetra planeri Bloch). Journal of Zoological, Systematics and Evolutionary Research 36, 85-99.

Swofford, D. L. (2003). PAUP*. Phylogenetic Analysis Using Parsimony (*and Other Methods). Version 4b.10. Massachusetts: Sinauer Associates.

Thompson, J. D., Gibson, T. J., Plewniak, F., Jeanmougin, F. \& Higgins, D. G. (1997). The Clustal X windows interface: flexible strategies for multiple sequence alignment aided by quality analysis tools. Nucleic Acids Research 24, 4876-4882.

Vladykov, V. D. \& Kott, E. (1979). Satellite species among the holarctic lampreys (Petromyzonidae). Canadian Journal of Zoology 57, 860-867.

White, M. M. \& Martin, H. R. (2009). Structure and conservation of tandem repeats in the mitochondrial DNA control region of the least brook lamprey (Lampetra aepyptera). Journal of Molecular Evolution 68, 715-723.

Zanandrea, G. (1959). Speciation among lampreys. Nature 184, 380. 